\title{
MARINE HUNTING AND FISHING ON THE COAST OF NORTH FENNOSCANDIA BEFORE CHRIST
}

(C) 2019

\author{
Kiseleva Alevtina Mikhailovna, master student of Archaeology Department \\ Murashkin Anton Igorevich, senior lecturer of Archaeology Department \\ Saint Petersburg State University (Saint Petersburg, Russian Federation)
}

\begin{abstract}
Archaeological evidence for marine hunting and fishing at the coast of the Barents Sea dates from $5000 \mathrm{cal} \mathrm{BC}$ to $0 \mathrm{cal} \mathrm{BC} / \mathrm{AD}$, encompassing the Neolithic, the Early Metal Period and the Early Iron Age. Among hunting and fishing equipment are bone and antler harpoon heads, fishhooks and leisters. Four periods of development of the tools were established on the basis of stable occurrence of the artefacts types in complexes (semisubterranean houses, shell middens, burials). The chronological boundaries of the periods were defined by the radiocarbon dates of this complexes: A - 5000-2500 cal BC, B - 2500-1600 cal BC, C - 1500-1100 cal BC, D - $900 \mathrm{cal}$ $\mathrm{BC}-0 \mathrm{cal} \mathrm{BC} / \mathrm{AD}$. The primary marine taxa exploited were pinnipeds and cetacean. The marine hunting was supplemented by catching Atlantic Cod and codfishes. Percentage ratio of animal bones from dated complexes indicates that the role of the seal and whale hunting had increased considerably since about $2500 \mathrm{cal} \mathrm{BC}$. This coincides with the appearance of toggling harpoons in hunting equipment. The exploitation of aquatic resources in the Early Iron Age (after $900 \mathrm{cal}$ BC) remained important in the subsistence economy. The transition to a primary exploitation of terrestrial resources at coastal locations is not observed.

Keywords: Northern Fennoscandia; Kola Peninsula; Northern Norway; Neolithic; Early Metal Age; Early Iron Age; periodization; chronology; marine hunting; fishing; bone inventory; fishhooks; harpoon heads; leisters; osteological analysis; hunting game Pinnipeds; Cetacean; Fish.
\end{abstract}

УДК 902.01

DOI 10.24411/2309-4370-2019-12213

Статья поступила в редакцию 04.02.2019

\section{НОВОИЛЬИНСКАЯ ПОСТНЕОЛИТИЧЕСКАЯ КУЛЬТУРА В СРЕДНЕМ И ВЕРХНЕМ ПРИКАМЬЕ}

(C) 2019

Лычагина Евгения Леонидовна, кандидат исторических наук, доцент кафедры Отечественной и всеобщей истории, археологии

Пермский государственный гуманитарно-педагогический университет (г. Пермь, Российская Федераџия)

Выборнов Александр Алексеевич, доктор исторических наук, профессор, заведующий кафедрой отечественной истории и археологии

Самарский государственный социально-педагогический университет (2. Самара, Российская Федераџия)

Жукова Ольга Владимировна, хранитель

Пермский краевой краеведческий музей (2. Пермь, Российская Федерачия)

Аннотащия. В статье анализируются материалы памятников новоильинской культуры Среднего и Верхнего Прикамья. Прослеживается история изучения вопроса, определяется степень изученности вопроса. Выделяются основные источники по теме, определяется их доброкачественность. Фиксируется местоположение стоянок и характерные параметры жилищ. Констатируется их сходство с неолитом. Приводится описание керамического и каменного инвентаря. Выделяются характерные и особенные признаки. Проводится сравнительный анализ комплексов с материалами позднего неолита, выявляется определенная схожесть. Рассматривается вопрос о наличии остатков металлообработки на памятниках новоильинской культуры. Делается вывод об отсутствии доказательств энеолитического характера стоянок новоильинского типа. Анализируется банк данных по радиоуглеродной хронологии новоильинских комплексов. Выделяются наиболее валидные значения. Определяется их хронологический интервал существования: 5200-4500 лет ВР. Затрагивается вопрос о генезисе новоильинской культуры Среднего Прикамья. Констатируется не только близость с культурой местного неолита, но и предполагается роль культур сопредельных территорий. Приводится сравнительный анализ с материалами красномостовского типа лесного Среднего Поволжья. Делается вывод об их хронологическом соотношении. Авторы приходят к выводу о постнеолитическом возрасте новоильинской культуры. Новоильинская культура входит в круг культур лесного Среднего и Верхнего Поволжья.

Ключевые слова: новоильинская культура; Среднее Прикамье; Верхнее Прикамье; памятники; жилища; керамика; гребенчатый штамп; каменный инвентарь; металлообработка; технико-технологический анализ керамики; радиоуглеродные даты; хронология; лесное Среднее Поволжье; красномостовский тип; постнеолит.

Изучение археологических культур лесной зоны Волго-Камья сопряжено с определенными трудностями, вызванными рядом обстоятельств. Во-первых, отсутствуют стратифицированные памятники, что не способствует определению объективной периодиза-

ции. Поэтому новоильинскую культуру одни исследователи помещали между гаринскими и борскими комплексами, а другие на более раннюю позицию. Во-вторых, на подавляющем большинстве памятников новоильинской культуры присутствуют артефак- 
ты более позднего времени, что затрудняет точное отнесение следов металлообработки к тому или иному комплексу. В-третьих, до недавнего времени отсутствовали радиоуглеродные даты, что не позволяло установить четкие хронологические рамки как новоильинских, так и гаринско-борских древностей. Bсе это делает вопрос о новоильинской культуре весьма актуальным. Поэтому целью настоящей статьи является определение периодизационной позиции новоильинской культуры.

К кругу культур постнеолитического облика, существовавших на территории Прикамья, относится новоильинская культура. Памятники новоильинской культуры известны на территории Верхней, Средней и Нижней Камы, в Камско-Вятском и Икско-Бельском междуречье в пределах Пермского края, Удмуртии, Северной Башкирии и Восточного Татарстана.

Первые памятники (Бор IV, Боровое Озеро II и Боровое Озеро III) были обнаружены в 1950 г. КАЭ ПГУ под руководством О.Н. Бадера в устье p. Чусовой [1, с. 11]. Во второй половине 1950-х гг. памятники с подобной керамикой были зафиксированы в зоне строительства Воткинской ГЭС, в южной части Среднего Прикамья - Гагарское II, Гагарское III, Новоильинское III, Усть-Паль, Бойцовское I, Тюремка I, Сауз II, Сауз III [2, с. 189-191; 3, с. 124$137 ; 4]$. Таким образом, уже в 1950-е гг. было обнаружено и исследовано раскопками более 10 памятников с так называемой «флажковой» керамикой. Термин «флажковая» керамика, был признан О.Н. Бадером неудачным, так как узор подобного вида встречался не так часто и далеко не на всех памятниках данной группы. Поэтому было предложено называть культуру гагарской или новоильинской по опорным памятникам, изученным в Среднем Прикамье [5, с. 60-75].

Изучение этой культуры было продолжено в 1970-80-е годы на территории Верхнего Прикамья, Икско-Бельского междуречья [6-8], Нижней Камы $[9$, с. 40-67], в бассейне р. Вятки $[10$, с. 70-95; 11, с. 5-19; 12, с. 4-18; 13, с. 89-123]. Комплексы поселений Муллино IV и Сауз III, аналогичные новоильинским, относились исследователями и к позднему этапу агидельской энеолитической культуры [14]. В XXI в. на интересуемой территории были проведены исследования новых новоильинских памятников [15, с. $177-183 ; 16$, с. $180-187]$.

На сегодняшний день новоильинские комплексы известны более чем на 30 археологических памятниках Волго-Камья. К наиболее крупным и хорошо изученным следует отнести поселения Новоильинское III, Гагарское III, Усть-Очер I, Сауз I, Сауз II, Татаро-Азибейское II, Русско-Азибейское III, Кочуровское IV, Среднее Шадбегово I [17, с. 33-37; 18]. При этом необходимо отметить, что большинство из перечисленных памятников - многослойные. Помимо новоильинского, на них могут присутствовать как более ранние комплексы, относящиеся к неолиту, так и материалы гаринской и еще более поздних культур (ерзовской, ананьинской и др.).

Памятники новоильинской культуры, как правило, располагались на невысоких боровых террасах. Подобное расположение во многом характерно и для неолитических стоянок. Поэтому неудивительно, что поселения новоильинской культуры нередко возни- кали на месте последних (Заюрчим, Чашкинское Озеро I, Сауз I, Сауз II, Среднее Шадбегово I и др.). Форма жилищ также близка к форме построек хуторского типа - подпрямоугольные, углубленные в материк до 1 м. Таким образом, можно проследить определенную преемственность в выборе мест для стоянок и форме жилищ между памятниками, относящимися к камской неолитической культуре и новоильинской.

Сосуды характеризуются полуяйцевидной формой с округлоконическим дном. Верхние части сосудов прямые или открытые. Срезы венчиков округлые или плоскоскошенные. Новым, по сравнению с неолитом, становятся пальцевые защипы на срезе, что делает венчик гофрированным (рис. 1: 7) Поверхность керамики орнаментирована средним (рис. 2: 2; рис. 3: 1) и коротким (рис. 3: 6, 7) гребенчатым штампом прямоугольной, овальной или изогнутой формы, ямчатыми вдавлениями различной формы (рис. 2: 4, 5; рис. 4: 1). По сравнению с неолитическим, орнамент новоильинской посуды более разреженный. Среди композиций преобладают наклонные, горизонтальные, вертикальные ряды (рис. 1: 2, 3; рис. 2: 6; рис. $3: 2$; рис. 4) представлен горизонтальный (рис. 1: 1; рис. 2: 1; рис. 3: 3) и вертикальный зигзаг. Значительно реже встречались более сложные узоры в виде ромбов, треугольников, «флажков», «решеток» (рис. 1: 6; рис. 2: 3; рис. 3: 5). «Шагающая гребенка», характерная для неолита, на новоильинских памятниках не обнаружена. При сравнении с керамикой лёвшинского этапа камской неолитической культуры были выявлены сходства по таким показателям, как форма сосудов и способы орнаментации [19, с. 80-86]. Технико-технологический анализ керамики показывает ее двукомпонентность и определенное сходство с посудой камской культуры [20]. В тоже время, часть новоильинской посуды на ряде памятников содержит органическую примесь, что позволяет конкретизировать ее периодизацию [21]. Таким образом, можно рассматривать керамику новоильинской культуры как продолжение камской традиции с некоторыми новациями.

Сырьем для изготовления орудий служили местные материалы. Характерной чертой является применение плитчатого кремня (рис. 5: 5). В технике раскалывания камня преобладала отщеповая индустрия, но для наконечников, ножей и острий могли браться и пластинчатые заготовки. Ведущими категориями орудий являются скребки, ножи, наконечники стрел. Кроме концевых с прямым или овальным лезвием (рис. 5: 6-10), представлены скребки-ножи на пластинчатых отщепах. Ножи прямолезвийные, иногда саблевидные (рис. 5: 11-12). Острия не имеют типологически устойчивых форм. Наконечники стрел имели листовидную с усеченным или подтреугольным черешком форму, реже иволистные (рис. 5: 1-4). Деревообрабатывающие орудия со шлифовкой представлены сериями небольших тесел, долот, топоров (рис. 5: 13-16). Таким образом, каменный инвентарь новоильинской культуры содержит много общих черт с инвентарем неолитических памятников камского типа. К таким чертам можно отнести использование плитчатого кремня, отщепово-пластинчатую индустрию, сходный набор орудий. 

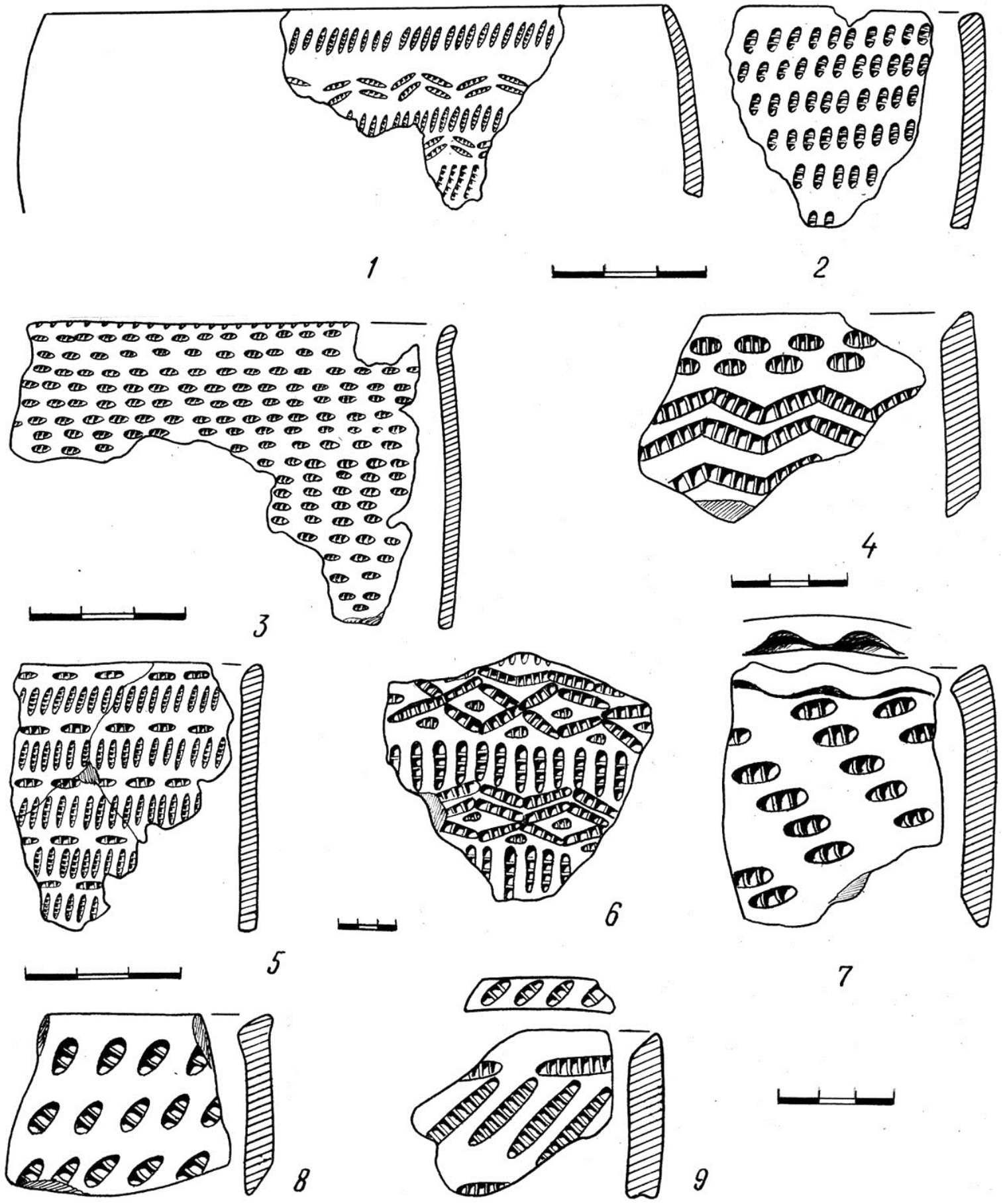

Рисунок 1 - Керамика новоильинского типа стоянок Кочуровское IV (образцы 1-5), Сауз I (образцы 6-9)

Следы меднолитейного производства обнаружены на поселениях Усть-Очер I, Новоильинское III, Гагарское III. Именно на основе присутствия изделий из меди на ряде памятников, новоильинская культура была отнесена к энеолиту. В пользу этой точки зрения приводились и другие аргументы [8]. В тоже время, необходимо отметить, что на всех памятниках, где присутствовал металл, имелся более поздний энеолитический слой, относящийся к гаринской культуре [22, с. 24-25]. Даже на таком условно «чистом» памятнике как Гагарское III поселение [18] обнаружено несколько фрагментов гаринского типа. Поэтому найденные здесь 22 предмета, связанных с металлообработкой, отнести однозначно к новоильинскому комплексу не совсем корректно. Кроме того, оно находится на одной дюне на незначительном расстоянии от Гагарского I и Гагарского II поселе- ний, а их основной комплекс относится к энеолитическим культурам с пористой керамикой. Поэтому обнаруженные на нем медные изделия также могли быть не связаны с основным комплексом памятника. Так или иначе, исследователи относили памятники новоильинской культуры не к позднему, а раннему энеолиту [13] или переходному периоду от неолита к энеолиту [23].

Чистых новоильинских древностей, не сопрягающихся с металлосодержащими энеолитическими гаринскими и более поздними материалами, мало Чашкинское озеро I, Шемети, Бор IV (верхнее поселение), Зверево, Кочуровское IV, Среднее Шадбегово I, Аркуль IV. На них не найдено следов цветной металлургии [18]. Поэтому вопрос о наличии собственного металла в новоильинской культуре остается дискуссионным. 

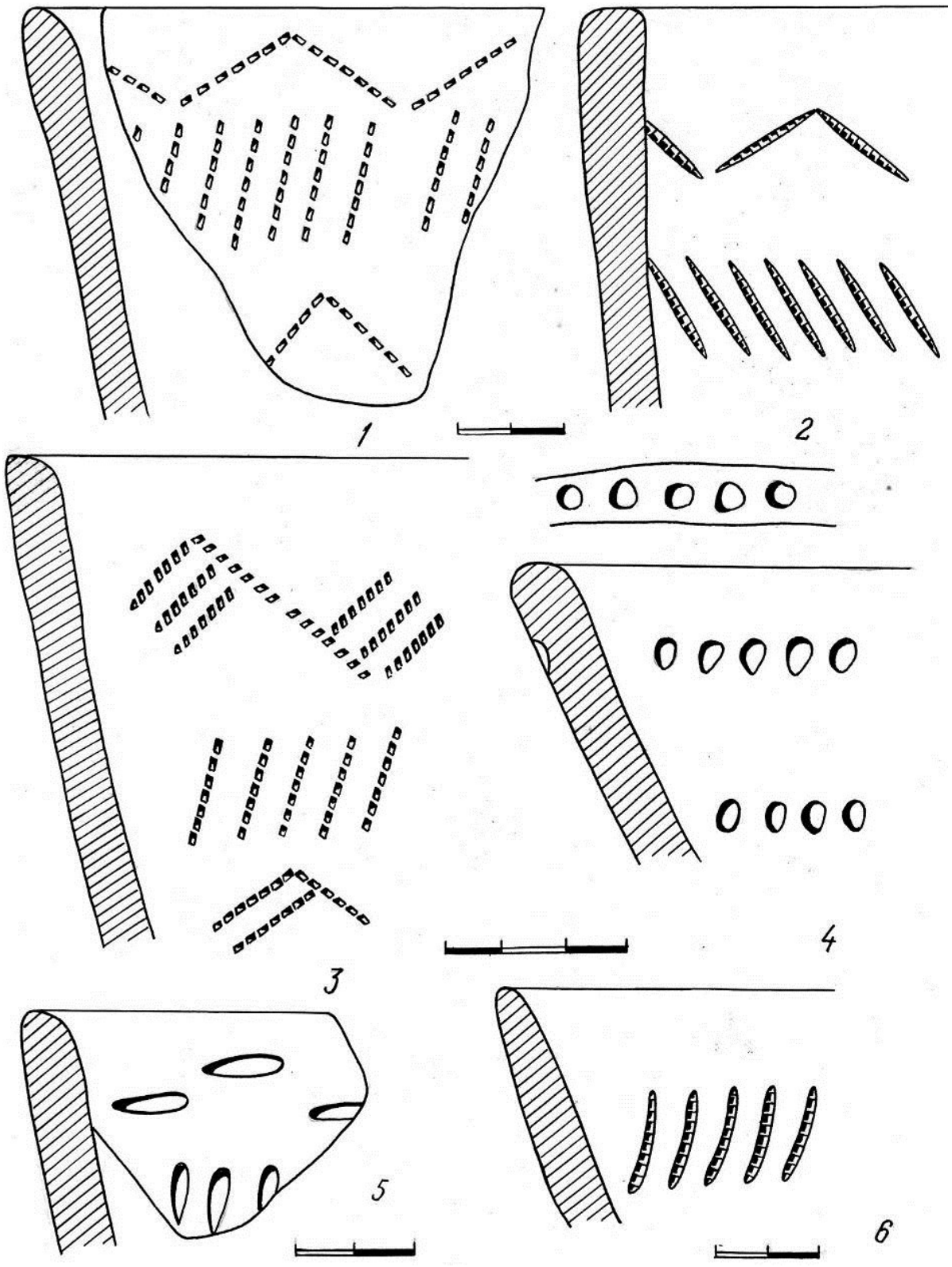

Рисунок 2 - Керамика новоильинского типа поселения Гагарское III (образцы 1-6)
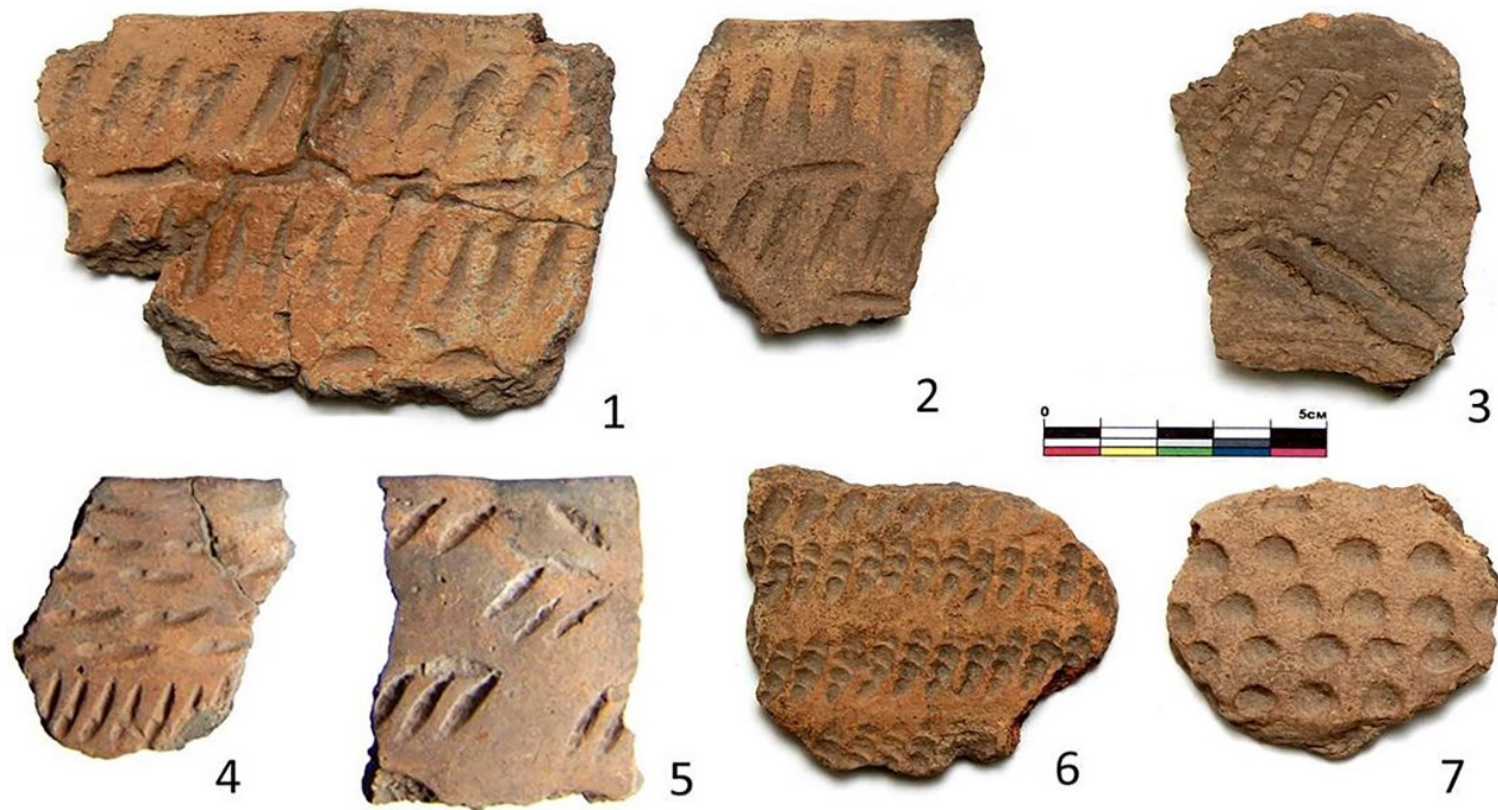

Рисунок 3 - Керамика новоильинского типа стоянки Сауз II (образцы 1-7) 

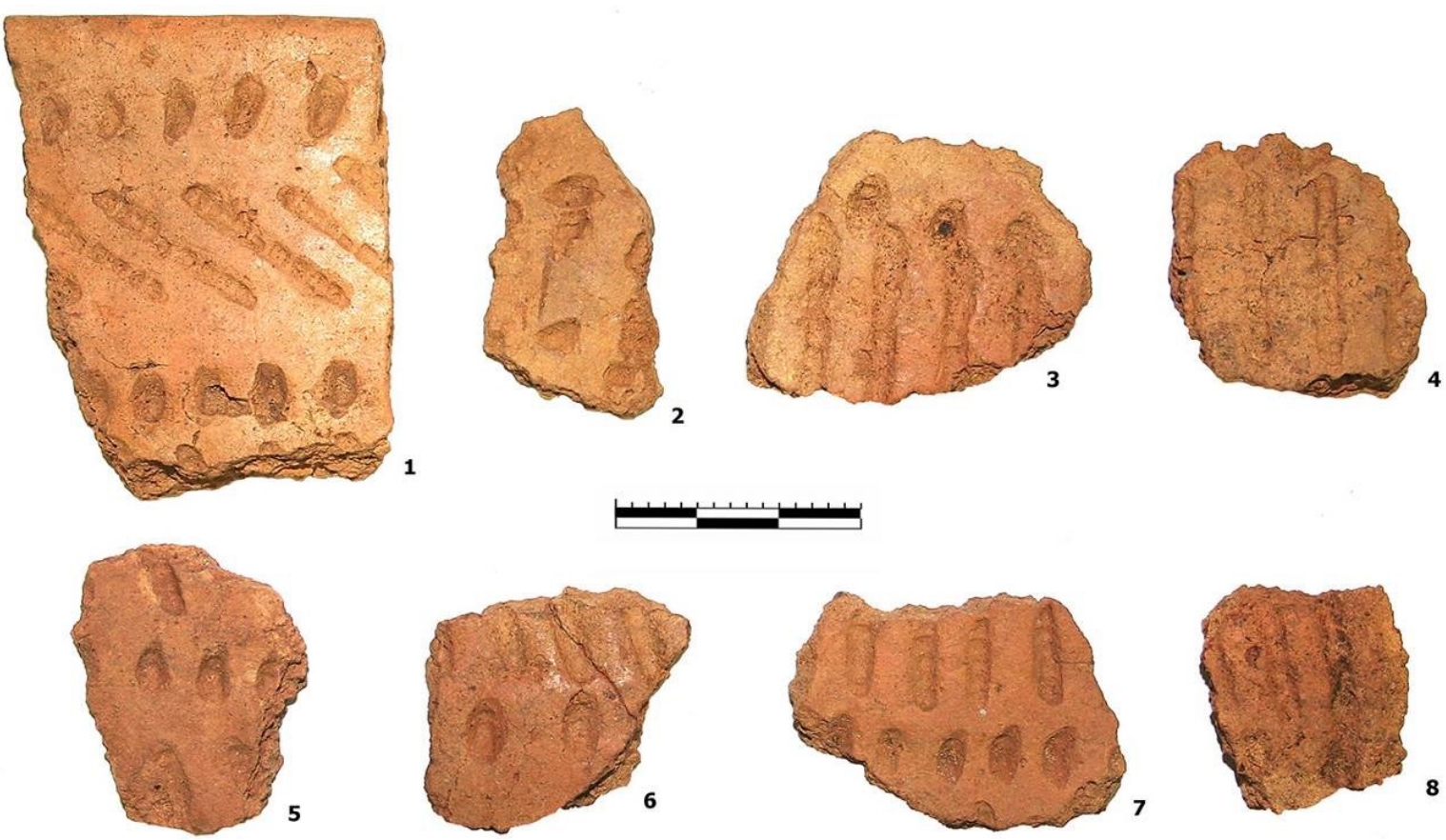

Рисунок 4 - Керамика новоильинского типа стоянки Чашкинское озеро I (образцы 1-8)

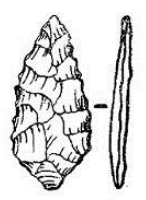

1

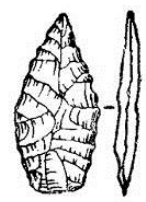

2

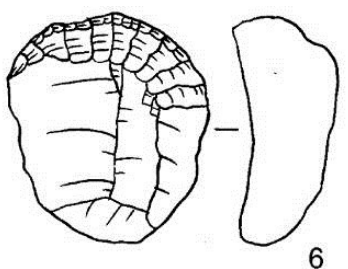

6
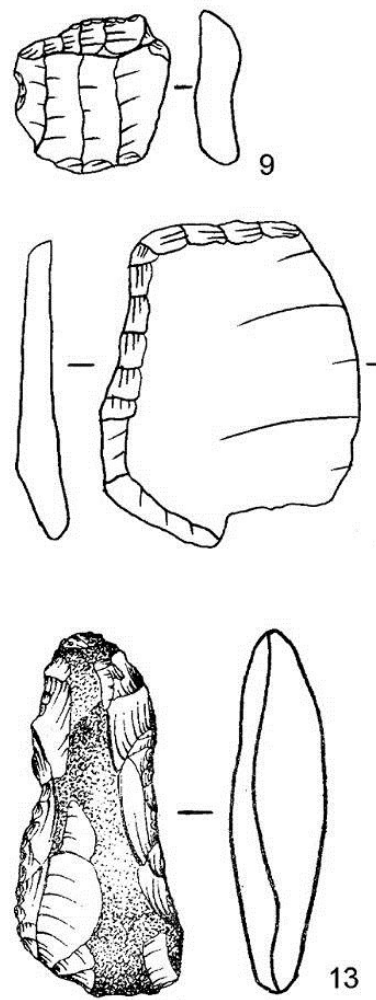

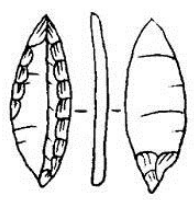

3
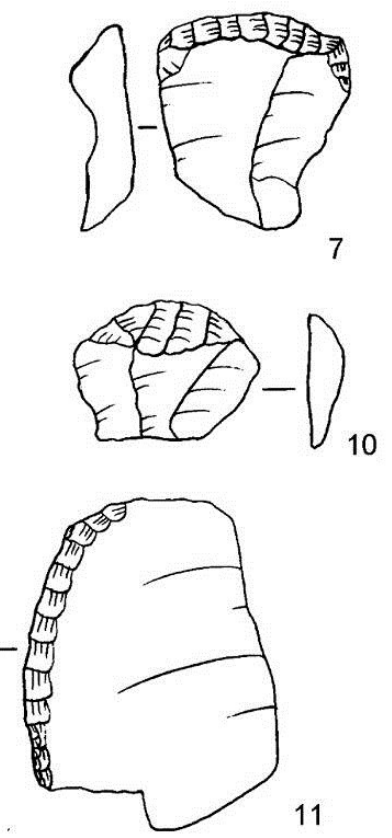

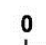

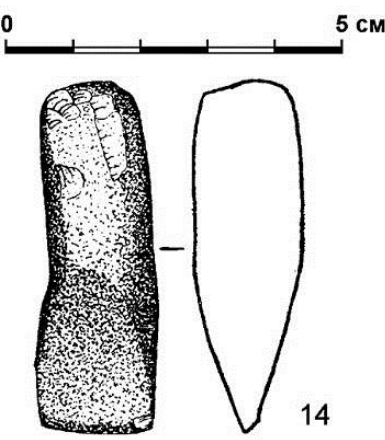

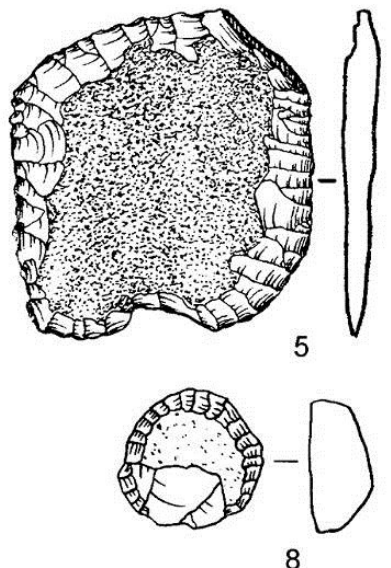

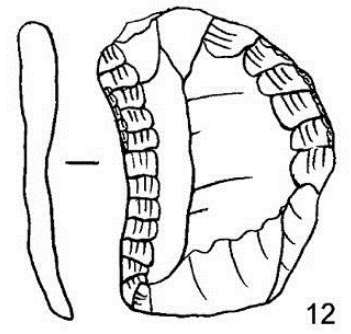

12
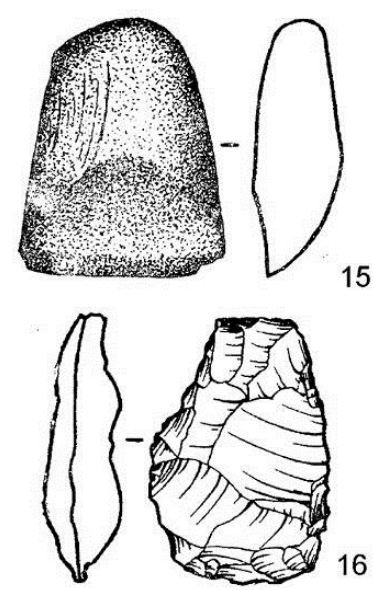

Рисунок 5 - Каменный инвентарь новоильинского типа Верхнего и Среднего Прикамья (образцы 1-16) 
На сегодняшний день, для памятников новоильинской культуры имеется 14 радиоуглеродных дат, полученных по разным материалам (нагару, углю, органике в керамике). Однако не все из них являются валидными. В качестве репера для определения возраста новоильинской культуры следует использовать дату по нагару для поселения Гагарское III $4910 \pm 40$ лет ВР [24]. К ней близки даты, полученные по органике в керамике с того же памятника, а также со стоянок Чашкинское Озеро I, Красное Плотбище и Гагарское II. Подтверждением этому являются результаты повторного датирования керамики поселения Сауз II [25, с. 143]. Мы полагаем, что время существования новоильинской культуры может быть отнесено от последней четверти IV тыс. (5200 ВР) до середины III тыс. до н.э. (4500 ВР). Проведенный анализ и имеющиеся радиоуглеродные датировки позволяют предполагать, что ранние новоильинские памятники появляются несколько позже левшинских, а поздние завершают свое развитие несколько раньше гаринских и борских.

Учитывая все вышеприведенные аргументы, новоильинскую культуру допустимо рассматривать как постнеолитическую.

Что касается появления новоильинской культуры в Среднем Прикамье, то ее исходной территорией, по мнению О.Н. Бадера, мог быть район р. Вятки или более южного (нижнекамского или волго-камского) Прикамья, а причиной явилось смещение лесостепной зоны на север в момент ксеротермического максимума и давление южных культур [1, с. 194-195]. Новые данные позволяют внести в эту гипотезу некоторые уточнения. Если нижней хронологической границей новоильинских комплексов является 5200 лет ВР, то это хорошо коррелирует с масштабными климатическими изменениями среднего голоцена [26]. Судя по серии радиоуглеродных дат, в это время в Волго-Камье (лесное Среднее Поволжье) фиксируются памятники красномостовского типа [27]. Их материалы столь близки новоильинским, что их рассматривали как локальный вариант последних
[21]. Можно констатировать аналогичность форм сосудов, способов нанесения узоров, мотивов и орнаментальных композиций (рис. 6). Уместно отметить одну историографическую деталь: стоянки красномостовского типа были открыты и исследованы на четверть века позднее новоильинских. Если бы ситуация была обратной, то тогда новоильинские материалы рассматривались как локальный вариант красномостовских. Наиболее значимое отличие проявляется в большем удельном весе компонентов ямочногребенчатой керамики (рис. 6: 2, 5, 6) в красномостовской посуде [28]. В данном случае можно лишь констатировать, что комплексы таких памятников как Кочуровское IV в Камско-Вятском междуречье, Сауз I и II в Нижнем Прикамье (рис. 1: 2), в большей степени сходны с красномостовскими. Это подтверждается как типолого-статистическим [29], так и технико-технологическим [30] анализами. Таким образом, не отрицая роли носителей чернашкинского типа [31] камской неолитической культуры в генезисе новоильиских комплексов, все же следует учитывать и юго-западный компонент. Примечательно, что на «чистых» красномостовских памятниках не обнаружено следов металлообработки, а следовательно, их носители не могли принести эту традицию в среду новоильинцев. Более того, судя по радиоуглеродным датам, хронологические рамки существования красномостовских комплексов несколько короче [32], чем диапазон функционирования новоильинских древностей Среднего Прикамья. В начале III тыс. до н.э. в марийском Поволжья, судя по радиоуглеродным датам, уже появляются памятники средневолжского волосово. Тем не менее, в период последней четверти IV тыс. до н.э. они составляли не только протоэнеолитический пласт, но и единство на уровне культурной области. Она не ограничивалась рамками Волго-Камья, так как западнее представлены памятники протоволосовского типа [33], имеющие ряд типологических параллелей с красномостовскими. Для них имеются и радиоуглеродные даты порядка 5200 лет ВР.

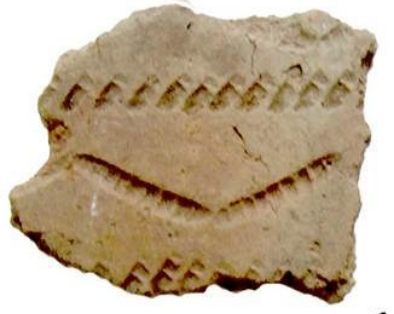

1

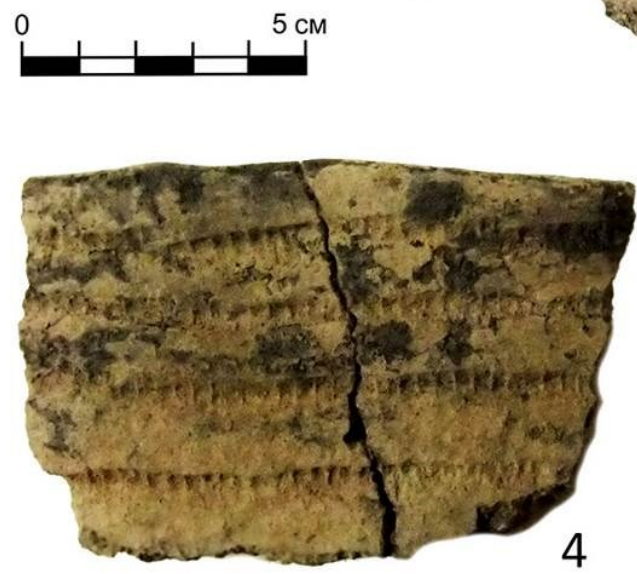

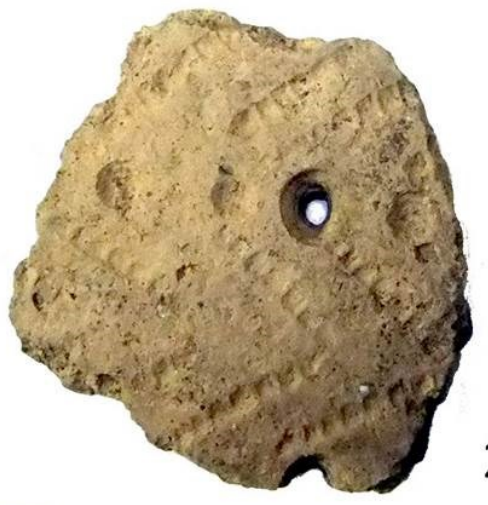

2

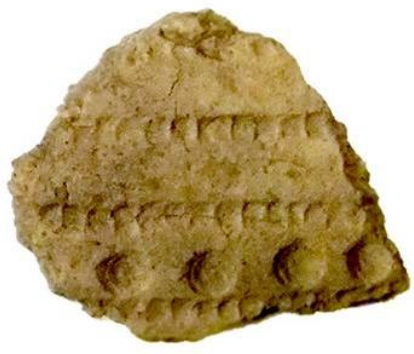

3

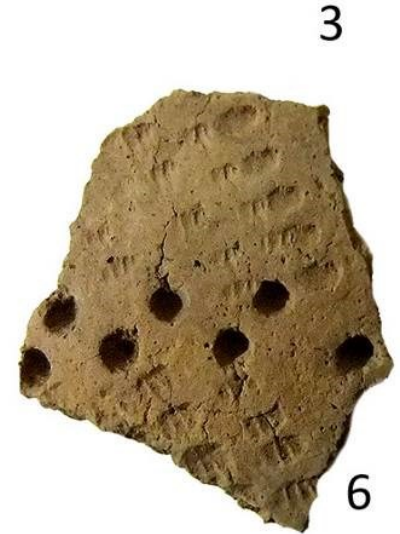

Рисунок 6 - Керамика красномостовского типа лесного Среднего Поволжья (образцы 1-6) 
Лычагина Е.Л., Выборнов А.А., Жукова О.В. 07.00.00 - исторические науки и археология Новоильинская постнеолитическая культура в Среднем и Верхнем Прикамье

Таким образом, можно констатировать отсутствие достоверных доказательств отнесения новоильинской культуры к эпохе раннего металла. Судя по серии радиоуглеродных дат, новоильинская культура занимает более раннюю хронологическую позицию, чем энеолитические гаринская и борская культуры. Прослеживается определенная степень близости памятников новоильинского и красномостовского типов. Это позволяет предполагать их вхождение в одну культурную область и на определенном этапе сосуществования составлять (вместе с протоволосовскими) протоэнеолитический пласт культур лесного Волго-Камья.

\section{Список литературы:}

1. Бадер О.Н. Поселения турбинского типа в Среднем Прикамье. М.: Наука, 1961. (Материалы и исследования по археологии СССР, № 99). 198 с.

2. Бадер О.Н. Поселения у Бойцова и вопрос периодизации среднекамской бронзы // Отчеты Камской (Воткинской) Археологической Экспедиции. 1961. Вып. 2. М.: ИА АН СССР. С. 110-272.

3. Бадер О.Н., Выборнов А.А. Саузовская II стоянка в устье р. Белой и некоторые проблемы неолита - энеолита Приуралья // Энеолит Восточной Европы. Куйбышев: КГПИ, 1980. С. 124-137.

4. Матюшин Г.Н. Мезолит и неолит Башкирии: автореф. дис. ... канд. ист. наук. М., 1964. 24 с.

5. Бадер О.Н. Третье Ново-Ильинское поселение // Отчеты Камской (Воткинской) Археологической Экспедиции. М.: ИА АН СССР, 1961. Вып. 2. С. 60-74.

6. Выборнов А.А., Овчинникова Н.В. Итоги изучения поселения Сауз II // Древние и средневековые культуры Поволжья. Куйбышев: Изд-во КГПИ, 1981. C. $33-52$.

7. Выборнов А.А., Обыденнов М.Ф., Обыденнова Г.Т. Поселение Сауз I в устье реки Белая // Эпоха меди юга Восточной Европы. Куйбышев: КГПИ, 1984. C. 3-21.

8. Выборнов А.А. «Флажковый» комплекс керамики Нижней Белой // Новые памятники археологии Волго-Камья. Йошкар-Ола: Изд-во МарНИИ, 1984. C. $50-63$.

9. Габяшев Р.С. Второе Татарско-Азибейское поселение // Древности Икско-Бельского междуречья. Казань: ИЯЛИ КФАН СССР, 1978. С. 40-66.

10. Гусенцова Т.М. Поселение Кочуровское IV в бассейне р. Кильмезь // Памятники эпохи энеолита и бронзы в бассейне р. Вятки. Ижевск: Изд-во УдГУ, 1980. С. 70-95.

11. Наговицин Л.А. Из истории изучения памятников эпохи энеолита и бронзы в бассейне р. Вятки // Памятники эпохи энеолита и бронзы в бассейне p. Вятки. Ижевск: Изд-во АН СССР УО Удмурт. ИЯЛИ, 1980. С. 3-18.

12. Наговицин Л.А. Энеолит бассейна р. Вятки: автореф. дис. ... канд. ист. наук. М., 1983. 20 с.

13. Наговицин Л.А. Периодизация энеолитических памятников Вятского края // Проблемы изучения каменного века Волго-Камья. Ижевск: УИИЯиЛУрО AH CCCP, 1984. C. 89-123.

14. Матюшин Г.Н. Энеолит Южного Урала. М.: Наука, 1982. 328 с.

15. Лычагина Е.Л. Стоянка Чашкинское Озеро I новый памятник новоильинской культуры в окрестностях г. Березники Пермского края // Региональные, социокультурные, политические и экономические процессы: опыт и перспективы. Березники, 2008. С. $177-184$.
16. Коренюк С.Н., Мельничук А.Ф. Жилищные комплексы эпохи палеометалла поселения Заюрчим // Археологическое наследие как отражение исторического опыта взаимодействия человека, природы, общества. Ижевск: Изд-во УдГУ, 2010. С. 180-187.

17. Лычагина Е.Л., Выборнов А.А. К вопросу о происхождении и хронологии новоильинской энеолитической культуры // Научный Татарстан. Гуманитарные науки. Археология и история. 2009. № 2. C. 33-37.

18. Денисов В.П., Мельничук А.Ф. Поселение Гагарское III в системе новоильинских древностей Пермского Приуралья // Вестник Пермского университета. 2014. Вып. 1 (24). С. 44-59.

19. Жукова О.В., Лычагина Е.Л. Сравнительная характеристика поздненеолитических и новоильинских комплексов керамики Верхнего и Среднего Прикамья // Вестник Пермского университета. 2012. Вып. 1. С. 80-86.

20. Батуева Н.С., Андреева (Ересько) О.В. Традиции изготовления керамической посуды эпох позднего неолита - раннего энеолита Верхнего и Среднего Прикамья // Актуальная археология. 4. Комплексные исследования в археологии. СПб.: ИИМК РАН, 2018. C. 128-132.

21. Наговицин Л.А. Дискуссионные проблемы в изучении новоильинской культуры // Вопросы археологии Урала. 1993. Вып. 21. С. 59-76.

22. Мельничук А.Ф. Поселение Усть-Очер I энеолитический памятник в Оханском Прикамье и проблемы изучения поселений новоильинского культурного круга // Вестник Пермского университета. 2011. № 1. C. 22-36.

23. Выборнов А.А. Неолит Прикамья: учеб. пособие по спецкурсу. Самара: Изд-во Самар. гос. пед. ин-та, 1992. $148 \mathrm{c.}$

24. Лычагина Е.Л. Ранний энеолит Прикамья. Вопросы хронологии новоильинской культуры // Проблемы периодизации и хронологии в археологии эпохи раннего металла Восточной Европы. СПб.: «СКИФИЯ-принт», 2013. С. 153-156.

25. Выборнов А.А., Кулькова М.А. Радиоуглеродное датирование керамики и проблемы хронологии энеолита Поволжья // Проблемы периодизации и хронологии в археологии эпохи раннего металла Восточной Европы. СПб.: СКИФИЯ-принт, 2013. С. 142-145.

26. Кулькова М.А. Климатические катастрофы в раннем и среднем голоцене и их влияние на древние сообщества // Радиоуглерод в археологических и палеоэкологических исследованиях. СПб.: Изд-во: «Теза», 2007. С. 316-333.

27. Никитин В.В. Красномостовские поселения финального неолита // Проблемы изучения каменного века Волго-Камья. Ижевск: УИИЯиЛУрО АН CCCP, 1984. C. 31-43.

28. Никитин В.В. Лесная полоса Волго-Камья на рубеже неолита-энеолита // Труды камской археолого-этнографической экспедиции. Вып. 8. Пермь: ПГСПУ, 2012. С. 67-76.

29. Ересько О.В., Шалапинин А.А. Сравнительный анализ новоильинской и красномостовской керамики // Известия Самарского научного центра РАН. 2015. Т. 17, № 3 (2). С. 507-513.

30. Ересько (Андреева) О.В. Сравнительный анализ ранних энеолитических комплексов среднего Прикамья и лесного Среднего Поволжья (на основе технико-технологического анализа) // Известия Са- 
марского научного центра РАН. 2018. Т. 20, № 3. C. 208-214.

31. Лычагина Е.Л. Поздний неолит Пермского Предуралья (к вопросу о соотношении памятников с накольчатой и гребенчатой керамикой): автореф. дис. ... канд. ист. наук. Казань, 2004. 24 с.

32. Кондратьев С.А., Шалапинин А.А. К проблеме хронологического соотношения комплексов позднего неолита-энеолита лесной зоны Среднего По- волжья // Известия Самарского научного центра РАН. 2011. T. 13, № 3. С. 259-263.

33. Сидоров В.В., Энговатова А.В. Протоволосовский этап или культура? // Тверской археологический сборник. Вып. 2. Тверь: ТГОМ, 1996. С. 164-182.

Статья публикуется при поддержке грантов РФФИ № 18-39-00059 «Ранние гончарные традиции населения Среднего Предуралья" и № 18-0900040.

\title{
NOVOILYINSKAYA POST-NEOLITHIC CULTURE IN THE MIDDLE AND UPPER KAMA RIVER REGION
}

(C) 2019

\author{
Lychagina Evgeniya Leonidovna, candidate of historical sciences, \\ associate professor of Domestic and World History, Archeology Department \\ Perm State Humanitarian Pedagogical University (Perm, Russian Federation) \\ Vybornov Alexander Alekseevich, doctor of historical sciences, professor, \\ head of Domestic History and Archeology Department \\ Samara State University of Social Sciences and Education (Samara, Russian Federation) \\ Zhukova Olga Vladimirovna, curator \\ Perm Local History Museum (Perm, Russian Federation)
}

Abstract. This paper deals with the analysis of the materials from the Novoilyinskaya culture monuments in the Middle Kama River region, traces the issue history and determines how much is known about it. The main sources of the issue are given and their reliability is determined here. The location of the sites and the characteristic parameters of dwellings are recorded. Their similarity with the Neolithic is stated. The ceramic and stone tools are described. The characteristic and special features are distinguished. A comparative analysis of the complexes with the materials of the late Neolithic is carried out, that reveals a certain similarity. The paper considers the issue of the metalwork residues presence at the Novoilyinskaya culture monuments. It is concluded that there is no evidence of the Eneolithic character of the Novoilyinskaya culture sites. The database on radiocarbon chronology of the Novoilyinskaya culture complexes is analyzed. The most valid values are highlighted. Their chronological interval of existence is determined: 5200-4500 BP. The issue of the genesis of the Novoilyinskaya culture in the Middle Kama River region is covered. The proximity with the culture of the local Neolithic is stated, as well as the role of cultures of adjacent territories is assumed. A comparative analysis with materials of the Krasnomostovsky type of the forest Middle Volga region is given. The conclusion about their chronological correlation is made. The authors also come to the conclusion about the Post-Neolithic age of the Novoilyinskaya culture. This culture is included in the range of the forest Middle and Upper Volga region cultures.

Keywords: Novoilyinskaya culture; Middle Kama River region; Upper Kama River region; monuments; dwellings; pottery; comb imprint; stone tools; metalwork; technological analysis of pottery; radiocarbon dates; chronology; forest Middle Volga region; Krasnomostovsky type; Post-Neolithic.

УДК 902.6

DOI 10.24411/2309-4370-2019-12214

Статья поступила в редакцию 01.02.2019

\section{НОВОИЛЬИНСКИЕ ПАМЯТНИКИ НИЖНЕГО ПРИКАМЬЯ: СОВРЕМЕННОЕ СОСТОЯНИЕ ПРОБЛЕМЫ}

(C) 2019

\author{
Морозов Виктор Владимирович, аспирант отдела первобытной археологии \\ Институт археологии им. А.Х. Халикова Академии наук Республики Татарстан \\ (2. Казань, Российская Федераџия)
}

\begin{abstract}
Аннотащия. В статье анализируются памятники новоильинской культуры Нижнего Прикамья, которые функционировали после распада камской неолитической культуры и до появления в регионе энеолитических культур с пористой (раковинной) керамикой. Анализ керамического комплекса новоильинской культуры позволяет утверждать, что по ряду показателей эта посуда близка гребенчатой керамике камской культуры. Отсутствие четких данных по стратиграфии и планиграфии, небольшая серия абсолютных дат не дают четкого представления о времени формирования и развития новоильинской культуры. Имеющиеся в настоящее время данные позволяют утверждать, что к последней четверти V тыс. cal BC самарские воротничковые (ивановские) традиции исчезают. В Нижнем Прикамье сформировывается специфичная керамика «неолитоидного» облика. При этом на новоильинской керамике Икско-Бельского междуречья фиксируются особенности, которые являются левшинскими реминисценциями, не характерными для Среднего и Верхнего Прикамья, это - наплывы с внутренней стороны венчика, ряды ямочно-жемчужных вдавлений под венчиком, закрытые формы посуды и орнамент «шагающая гребенка». Близость керамических комплексов новоильинских памятников с поздненеолитической керамикой камской культуры, наличие радиоуглеродных дат, от-
\end{abstract}

